\title{
A expressão cênica como elemento facilitador da performance no coro juvenil
}

\author{
Patricia Costa (UNIRIO-PPGM, Rio de Janeiro) \\ pccantocoral@gmail.com
}

Resumo. 0 presente artigo nasceu do desejo de pesquisar e divulgar este excelente veículo facilitador do canto coral - sobretudo para adolescentes - que é a expressão cênica. Tal recurso vem oferecer uma gama maior de possibilidades criativas e soluções originais para o desenvolvimento da linguagem coral, além de instigar os envolvidos ao exercício do autoconhecimento. Este trabalho é parte de pesquisa do Mestrado em Música desenvolvido na UNIRIO.

Palavras-chave: coro juvenil, canto coral, expressão cênica, ensino musical para adolescentes.

\section{Scenic expression as a facilitator in the youth choir performance}

Abstract. The present paper results from the need to research and promote scenic expression as an ideal facilitator for singing, especially among adolescents. It may offer a wider range of creative possibilities and original solutions for the development of the choral language, besides encouraging the exercise of self-knowledge. This paper is part of a Masters Degree in Music research developed at UNIRIO (Brazil).

Keywords: youth choir, choral singing, scenic expression stage acting, music teaching for teenagers.

\section{1 - Introdução}

A pouca popularidade do coro juvenil sempre atraiu minha atenção, por compreender os benefícios da atividade para esta faixa etária e, ao mesmo tempo, perceber a rejeição dos jovens e adolescentes ao canto coral.

Quando adolescente, fazia alusão a uma estética musical ultrapassada, o que impossibilitava a apreciação da música produzida pela junção das vozes fosse ela bem executada ou não. Minha entrada no canto coral como cantora se deu em 1978 pelo prazer de cantar, tão somente. Tive a oportunidade de pertencer a grupos cujos regentes traziam uma diversificada bagagem musical (Jaques Morelenbaum, John Neschling e Carlos Alberto Figueiredo, no Brasil e Robert Kingsbury nos EUA), mas que mantinham a estética européia do canto em grupo como foco de seus trabalhos.

Após a experiência com Marcos Leite na Orquestra de Vozes Garganta Profunda entre 1986 e 1987, pude tomar contato com outra concepção coral, voltada para a busca de uma estética diferenciada, focalizando a performance e com elementos cênicos incluídos em seus ensaios e apresentações.

Concomitantemente, iniciava formação em Artes Cênicas na CAL (Casa das Artes de Laranjeiras) e já atuava em inúmeras peças de teatro, além de participações como atriz de televisão (novelas e comerciais).
Alguns anos depois, passei a lecionar na CAL e na Escola-Parque/RJ (Teatro para Crianças e Adolescentes), podendo então compreender o universo libertador que o jogo teatral oferecia mesmo àqueles que não tinham pretensões de seguir carreira.

Tal experiência levou-me a perceber a expressão cênica como recurso para atingir jovens que, assim como eu, rejeitavam a atividade coral, quer fosse participando de um coro ou simplesmente se dispondo a assistir a um concerto.

Hoje, a trajetória de 15 anos de experiência como regente de coro juvenil, iniciada no Colégio São Vicente de Paulo (Rio de Janeiro) tornou-se objeto de minha pesquisa, sobretudo pelo alcance do projeto. Iniciado com vinte e nove moças e dois rapazes em abril de 1993, hoje comporta quatro coros juvenis, totalizando aproximadamente 130 jovens e adolescentes de ambos os sexos, além dos dois coros adultos compostos de pais e amigos, abertos pelo incentivo de meus próprios alunos. A implementação da atividade foi possível graças à junção teatro/música, cujo atrativo teve forte impacto ao grupo de estudantes.

Grande parte dos adolescentes brasileiros residentes no Rio de Janeiro desconhece ou não se interessa pela prática coral, por ser esta uma atividade rodeada de preconceitos. A associação com a estética do canto orfeônico de outrora e com o gosto da atividade pelo 
pessoal da terceira idade ou ainda a identificação como uma prática infantil, aliados à invisibilidade na mídia, em nada incentivam os jovens a perceberem no canto coral a possibilidade de veículo de expressão e prazer de sua faixa etária.

Embora o jovem da atualidade não tenha vivido a experiência do canto orfeônico, a singularidade daquela sonoridade coral the é muito evidente, uma vez que sua antiga estética seja até hoje explorada pela mídia sempre que mencionada a palavra "coral".

Como exemplo recente, o Especial de Roberto Carlos em dezembro de 2007, exibido em cadeia nacional pela Rede Globo. Em determinado momento, houve a participação do renomado coral Canarinhos de Petrópolis. Adentraram ao palco meninos e rapazes que, embora muito eficientes vocalmente, não tiveram sua habilidade explicitada posto que a sonorização daquele momento em nada Ihes beneficiasse. Pela expressão facial (ou falta de) dos coralistas, era flagrante a ausência de qualquer intenção neste sentido. Portanto, restava ao telespectador a visão de um grupo de crianças e adolescentes sem expressão, despersonalizado pelo uniforme (batas vermelhas compridas e pesadas) e, ao fundo, a captação (e, por conseguinte, o destaque) apenas das vozes com maior vibrato; exatamente a mesma concepção do canto orfeônico de outrora.

KERR (2006, p.237), denunciando a necessidade de revermos o papel do canto coral na atualidade, declara:

\footnotetext{
Urge ouvirmos, vermos e experimentarmos o que está acontecendo ao nosso redor, na busca da 'consciência' das próprias modificações perceptivas que estamos sofrendo em função do ambiente e que nele estamos provocando.
}

0 regente dedicado ao coro e, sobretudo, ao coro juvenil precisa se armar de diversas estratégias para obter sucesso junto aos adolescentes na atividade. Dentre estas, a expressão cênica pode ser um excelente recurso para gerar ou manter o entusiasmo dos cantores em geral, e dos cantores jovens, particularmente.

A grande mudança estética decorrida há mais de 30 anos pela influência de regentes como Marcos Leite e Samuel Kerr, ${ }^{1}$ dentre outros, não foi suficiente para que se estimulasse um estudo aprofundado e sistemático. Com base na experiência de 25 anos como cantora e 15 como regente, posso afirmar que, muito embora uma mudança de abordagem na prática coral tenha se dado ainda por volta dos anos 80 , poucos regentes se dedicam hoje ao estudo mais aprofundado e sistemático das conseqüências da adição da expressão cênica à atividade coral no Brasil, conforme evidencia esta pesquisa. Os trabalhos citados a seguir são alguns dos poucos dedicados a este tema, exemplos encontrados na revisão de literatura, indicando que há ainda um vasto campo a ser estudado. Por conseguinte, esta falta de literatura reduz a fonte de dados a depoimentos pessoais.
Num breve levantamento através da ARCl (Associação de Regentes de Coros Infantis) e ABRC (Associação Brasileira de Regentes Corais) foram encontrados poucos coros juvenis com ênfase na expressão cênica no Rio de Janeiro; também não foi possivel listar profissionais (diretores cênicos) específicos para esta função com corais, apenas com grupos vocais. Entretanto, nos demais estados brasileiros citamos o trabalho de Jonas Nogueira à frente do Coral Juvenil do Instituto Metodista Mackenzie (São Paulo), que grande sucesso fez nos anos 90. Destaca-se na atualidade o trabalho de Silmara Drezza e Vastí Atique (Jundiaí, SP) e o coral do Projeto Cariúnas (Belo Horizonte, MG), dirigido por Vivian Assis, além de Agnes Schmelling em São Leopoldo, no Rio Grande do Sul. Foram encontrados também nomes sempre ligados a coro juvenil com auxílio de direção cênica, como Mara Campos, Ana Yara Campos e Gisele Cruz.

Apesar das inúmeras vantagens percebidas após a introdução de elementos cênicos no trabalho coral, ainda são escassos os corais que objetivam se utilizar destas convenientes estratégias. Curiosamente, a dificuldade de difusão da atividade coral entre jovens e adolescentes poderia ser minimizada pela cativante abordagem multifacetada que o canto expressivo nos oferece podendo, outrossim, alimentar a constante sede de renovação e questionamento de nossos jovens cantores.

\section{2 - Características}

0 trabalho ao qual me refiro neste artigo, que é um recorte de minha dissertação de mestrado na UNIRIO, embora tenha caráter pedagógico por ser desenvolvido em escolas e por envolver adolescentes, busca o aprimoramento musical/vocal dos participantes utilizando, para isto, os artifícios da linguagem teatral. Não há neste coro a obrigação de cumprir-se uma programação curricular escolar, mas também não se trata de um grupo cujo objetivo se limite à performance.

Entenda-se por coro juvenil o grupo formado por cantores adolescentes e jovens, entre 12 e 20 anos, aproximadamente. $^{2}$ É fundamental observar-se este período como de importante e delicada instabilidade, tanto em aspectos físicos como emocionais. 0 inevitável processo de autoconhecimento e a busca de identidade através do coletivo se aliam, reforçando a atividade coral como uma alternativa de solução para estas necessidades. A expressão cênica vem, portanto, unir-se ao veículo, diversificando e aprofundando a investigação das possibilidades de expressão do jovem, de forma criativa e prazerosa ainda que o processo em si possa, eventualmente, trazer o desconforto da percepção das limitações do indivíduo.

Baseando-se na idéia de que o adolescente tem no grupo o material necessário para trabalhar e perceber suas identificações, o desenvolvimento da personalidade expressiva do grupo torna-se fator muito importante na atividade de coro juvenil. Através desta identificação, 0 jovem pode se sentir amparado, acolhido e seguro para 
o exercício de suas afirmações, utilizando muitas vezes o grupo coral como facilitador ou catalisador de suas próprias colocações no mundo.

Embora o jovem ainda não tenha muita experiência de vida ou bagagem pessoal, o senso de investigação, a curiosidade, a experimentação e a ousadia da criação são características da juventude e devem ser sempre exploradas.

Regente de grupos com intensa estrutura cênica, cujo trabalho abriu portas para uma nova expressão dos grupos corais cariocas a partir da década de 80 , Marcos Leite atesta esse poder investigativo de seus coralistas (em sua maioria, muito jovens, naturalmente). Tendo sabido aproveitar o produto final da liberdade de expressão e da intenção teatral de seus grupos mais importantes, como o Cobra Coral e a Orquestra de Vozes Garganta Profunda, sua linguagem surgiu como um divisor de águas na performance do que se conhecia como canto coral até então, segundo PIZZI (2005 apud RUIZ, 2004).

Uma caracteristica desta fase da vida é a necessidade que o jovem tem de sentir-se parte de algum grupo (RAPPAPORT, 1999). Uma vez inserido e aceito, a atividade coral pode estimular a percepção do outro dentro do grupo, desenvolvendo no adolescente o senso de coletividade e da preocupação com o todo. A necessidade de inter-relações e a consciência do crescimento pessoal através da relação com o outro faz da atividade coral um meio estratégico de grande alcance, mesmo para os jovens mais tímidos.

Porém, independente da faixa etária, quanto mais conhecimento do outro, mais confiança e mais ousadia na colocação. É fundamental que haja um investimento na aproximação dos participantes de um coral para que estes possam render ao máximo, sentindo-se livres para experimentar e sem se sentirem patrulhados ou criticados pelos colegas. "Antes de trabalhar uma postura cênica, movimento, é preciso todo um trabalho de confiança interno do grupo, desenvolver a confiança. $A$ movimentação é conseqüência de um laboratório" (COSTA apud SANTOS, 2003, p.15).

A participação do regente nas atividades voltadas para 0 fazer teatral é fundamental para estabelecer esta atmosfera de confiança. Vendo seu líder envolvido e empenhado, o coro se sente impelido a tomar parte do jogo. Novaes (SANTOS, 2003) compartilha desta mesma constatação, afirmando que "o regente tem que viver aquilo que ele está querendo do grupo, aí impregna" (p.14).

0 excesso de autocrítica pode levar o jovem a dificuldades no processo de investigação ou ainda ao desestímulo no trabalho em si. Portanto, é muito importante que o cantor tenha sido persuadido pela proposta e confie na sua direção. Uma vez identificado com a linguagem de um determinado grupo, o jovem passa a defender suas idéias com muita garra e paixão, obtendo resultados importantes para sua satisfação pessoal, que podem gerar formas criativas de comunicação extra-musical.

Segundo FIGUEIREDO (2006, p.8), "Um coro é uma espécie de tribo, com personagens essenciais, tais como os cantores e 0 regente; rituais típicos, tais como ensaios e apresentações; e objetos cultuais imprescindiveis, tais como a música e a partitura, sua representante material [...]." (grifo nosso)

Novaes, novamente citada por SANTOS (2003), também se utiliza da expressão, afirmando que "para que a criação seja real e inovadora, tem-se que ousar, e para isso é preciso a confiança na tribo. Aí começa-se a criar sem julgar, importantíssimo isso, não julgar. É errar mesmo, sem medo. É preciso tempo para isso" (p.29).(grifo nosso)

Seu argumento reforça esta necessidade de uma atmosfera saudável e livre de críticas para que o lado criativo não seja prejudicado.

\section{3 - Conceituando expressão cênica para corais}

0 conceito de expressão cênica defendido neste texto é o de um trabalho que promova o enriquecimento da experiência coral e da comunicação entre cantor e platéia, além do crescimento pessoal citado anteriormente. A teatralização de um espetáculo - ou mesmo apenas de uma música - empresta elementos extras à interpretação dos cantores podendo fazer novas conexões com a platéia, além da comunicação musical já esperada. PUEBLA (2004) sustenta que "o primeiro contato do público com o Coro é visual" (p.169). Portanto, faz sentido o cuidado com a postura cênica do grupo, ainda que esta se resuma aos protocolos de chegada e saída do palco e agradecimento às palmas.

Carlos Alberto Figueiredo, renomado regente coral que atua na cidade do Rio de Janeiro, em depoimento informal, alega que mesmo em seu coro - que não tem pretensão cênica - o ensaio de entrada e saída do palco possibilita uma segurança nos cantores que resulta em melhor resultado musical.

0 método Suzuki igualmente defende esta preparação, sendo senso comum a necessidade do ensaio de entradas e saídas do palco, conforme citado por Suray Soren ${ }^{3}$ em recente evento no Rio de Janeiro.

Muitas vezes também, a expressão cênica se inicia mesmo antes da entrada no palco, quando os coralistas vêm cantando já desde a coxia.

Observações empíricas durante 15 anos atestam sua importância.

0 uso da expressão cênica adotado neste trabalho não é aquele que pretende transformar os cantores em atores, embora se saiba que o potencial de atuação no palco é inerente ao ser humano. VIOLA SPOLIN, eu seu livro Improvisação para o Teatro (1963), afirma: 
Todas as pessoas são capazes de atuar no palco. Todas as pessoas são capazes de improvisar. As pessoas que desejarem são capazes de jogar e aprender a ter valor no palco (p.3)

Compreender o texto de uma peça é fundamental. Saber dizê-lo com clareza, também. Que benefícios encontramos no processo de exploração cênica em relação ao texto/ letra de uma determinada música? 0 cuidado com a poesia fica bastante evidenciado, uma vez que a mesma é um excelente recurso de expressão, componente forte da obra e, muitas vezes determinante para direcionarmos o trabalho para esta ou aquela abordagem. "Temos que trabalhar o sentimento que traz aquela canção, pensar no texto. Se tem poesia, tem que ser dita, e bem dita" (COSTA apud SANTOS, 2003, p.18). Através do texto, é possivel percebermos as intenções do autor/compositor; podemos, outrossim, brincar com as imagens que este texto suscita, evitando acentuar elementos óbvios. Poesia nem sempre se explica. Por exemplo, na canção Lua, Lua, Lua, Lua montada pelo coro juvenil São Vicente a Cappella (sob a direção desta pesquisadora) foram utilizadas bolas brancas - manipuladas pelos cantores - cujo propósito era criar a idéia de leveza e fluidez que a música pedia. Obteve-se um efeito de grande impacto visual sem cair na obviedade mais concreta do texto de Caetano Veloso. Neste sentido, as bolas utilizadas na canção descrita acima não representavam a lua e, sim, o subtexto daquela poesia.

Observação a ser considerada por aqueles que pesquisam a linguagem teatral no canto coral incide no fato de que nem todo cantor tem interesse ou disponibilidade emocional para lidar com o palco no que tange à expressão cênica. Esta constatação requer, inclusive, muito tato para que algumas inibições sejam vencidas sem traumatizar 0 cantor. Por outro lado, a investigação e o exercício cênico promovem um maior conhecimento de si, estimulando autoconfiança e segurança suficientes para prováveis mudanças no rendimento da performance do cantor. Tal constatação pode ser atestada no questionário transcrito por SANTOS (1999) onde se percebe os amplos benefícios da atividade, através do relato de experiência de uma cantora bastante retraída que se viu modificada em vários aspectos pelo trabalho cênico/coral.

0 exercício cênico pode atenuar o medo do palco uma vez que a elaboração desta linguagem demanda reflexão, repetição, exploração e investigação, através de jogos teatrais e dinâmicas de grupo. Incentivado por estes exercícios, o cantor dedicado toma constante contato com seus processos e receios, podendo aprender a enfrentálos e até determinar atitudes que solucionem possiveis impedimentos na realização da performance.

Ocorre que comumente os regentes não sabem a quem recorrer para utilizar técnicas teatrais com seus corais. Nem todo ator está apto a dirigir cenicamente um trabalho coral. Nem todo diretor cênico percebe o coro como um elenco diferente, com demandas e necessidades especificas. $E$, o mais perigoso, poucos regentes possuem alguma formação ou experiência para desenvolverem esta faceta com seus corais, contando apenas com seu bom senso e intuição. Em conseqüência disso, não é raro encontrarmos grupos que se utilizam, equivocadamente, de gestos com as mãos para sublinhar o texto cantado e assumem isto como exploração cênica.

A afirmação acima é corroborada pela opinião de Marcos Leite, concedida em palestra no Fórum RioAcappella (no Rio de Janeiro) em junho de 2001. 0 regente relatou que seu filho Rafael, então com cinco anos, adotara uma certa "coreografia" toda vez que entoava uma canção aprendida na escola. Não conseguia desconectar a canção daquele movimento corporal. Observa-se atualmente que de fato existem muitos grupos vocais ou corais, sobretudo de crianças e adolescentes (cujo repertório é de predominância popular) que se movimentam oscilando de um lado para o outro. Este movimento não é semelhante aos gestos que se ensinam na educação infantil conforme acusa FUKS (1991), mas sim de um movimento pendular hipnótico que parece sofrer a influência da estética do coro gospel americano.

Todavia é interessante notar que, sem tal coreografia, os coralistas não parecem apreciar tanto o fazer musical. Insuficientes critérios musicais à parte, seria isto uma transformação estética da prática, no intuito de tornála mais atual e menos tradicional? Será que tudo que é cantado combina com esta postura / movimento? 0 diretor do coro deverá ter bom senso para dosar os momentos em que incluirá movimentos. Expressão cênica não é apenas dançar ao som de uma música; como exposto acima, é utilizar qualquer recurso visual e/ou dramático.

SANTOS (1999) sustenta que, uma vez ampliadas as possibilidades de desenvolvimento de um coral, o regente e sua experiência musical já não são mais suficientes para este tipo de abordagem; outros profissionais tiveram que ser incluidos.

OLIVEIRA (1998) sublinha esta modificação, observando que a mudança de linguagem e da função do regente à frente de seu coro abriu espaço para que outras funções fossem exercidas.

0 que antes era coro, regente e arranjador, transformouse lentamente em: coro, regente, arranjador, compositor, regente de palco, orientador vocal, orientador corporal, figurinista, programador visual, produtor, diretor cênico, diretor musical, diretor administrativo, diretor artístico (p.8).

A prática coral, tanto no meio educacional quanto no meio artístico, é uma arte invisível, i.e., não aparece na mídia, não é valorizada pela população em geral, não dá lucro. Este baixo status faz com que sua platéia freqüentemente seja constituída apenas por parentes $\mathrm{e}$ amigos dos cantores, além de outros coralistas também envolvidos pela arte do canto em grupo. Mesmo em relação a coros profissionais como Garganta Profunda 
(nos anos 80) e Coro de Câmara Pro Arte (na atualidade) esta incidência é bastante emblemática da situação, o que nos leva a inferir de que o brasileiro em geral - ou senão o público carioca, pelo menos - não prestigia ou paga para ver espetáculo coral. Esta peculiaridade faz com que o nível de crítica da platéia seja condescendente resultando numa geração de grupos corais com tendência a fazer graça, posto que o riso desta platéia, especificamente, ocorra com facilidade.

Resta a escolha cuidadosa de um diretor cênico ou o investimento do próprio regente na sua formação extra-musical para que os resultados obtidos não sejam gratuitos ou pouco criativos, proporcionando prazer e estímulo a todos os envolvidos.

Em seu texto "O Canto em Cena" para o $2^{\circ}$ Congresso Internacional SESC / ARCI de Regência Coral (2004), o diretor cênico Reynaldo Puebla defende que "todos os coros que se apresentam SÃO cênicos, pois eles ESTÃO em cena" (p. 169, grifos do original). Partindo-se deste raciocínio não é difícil entender porque a exploração teatral do trabalho coral costuma produzir resultados tão bem aceitos pelas platéias. A performance engloba diversos apelos além do resultado musical e - ponderemos - 0 espectador que vai a uma apresentação não está com seu foco de atenção apenas no seu aparelho auditivo. Colorir a interpretação com recursos que vão ampliar o sentido de comunicação coro/platéia de forma extra-musical e que poderão atuar diretamente no fazer musical, é um trunfo que pode despertar muito prazer tanto nas descobertas quanto na realização do espetáculo.

\section{4 - Vantagens do recurso cênico}

Esta pesquisa busca estratégias para tornar a atividade coral mais atraente para o adolescente, aproveitando diversas vias de expressão. A expressão cênica é apenas uma delas. Embora não esteja sendo aqui defendida nenhuma obrigação na adoção de recurso cênico em coral, é fato que este permite também um aprofundamento na expressão de sentimentos. Estando o cantor (não ator) estimulado pelo jogo cênico - encarado, neste caso, como um "faz-de-conta" - ou ainda pela construção de um personagem, mesmo que isto se dê de forma rudimentar devido a pouca instrumentalização do não ator, a sensação de distanciamento advinda da consciência da diferença entre a ação do cantor e a ação do personagem beneficia, em muito, a naturalidade e a disponibilidade de criação do leigo. Uma vez compreendido o jogo teatral, o comprometimento com a atuação se altera, deixando o caminho livre para que as ações sejam assumidas não mais pelo cantor e sim pelo personagem construido, resultando muitas vezes no desbravamento de patamares jamais cogitados pelo indivíduo.

A acuidade musical pode ganhar novos coloridos, a partir da proposta teatral. Buscando recursos cênicos, muitos ganhos musicais e/ou vocais podem ser descobertos, por exemplo. Da mesma maneira, pode-se conseguir uma homogeneidade na intenção de atuação de cada indivíduo do grupo podendo levar, inclusive, a um equilíbrio tímbrico, tomando-se como ponto de partida uma proposta consistente de direção da atuação do cantor (ou do grupo). ${ }^{4}$

Muitas vezes, a movimentação propõe uma coreografia que facilita a absorção ou fixação do texto da música ou mesmo de determinada passagem com dificuldade rítmica, por exemplo; ou seja, pode otimizar o resultado do indivíduo.

No I Concurso FUNARTE de Canto Coral, em 1997, o coro juvenil do Colégio São Vicente de Paulo tinha como tarefa executar uma peça de Francisco Mignone. Foi escolhida a música $A$ Velha Cotó, de difíceis bordaduras e notável agilidade vocal. Optou-se por fazer uma verdadeira coreografia, com os rapazes no papel de velhinhas, fazendo uso das echarpes que compunham o figurino das meninas que estavam à sua frente. Tal determinação auxiliou tanto na intenção do texto como também na memorização das passagens, pois a marcação das ações indicava também a frase musical. Além disso, a inspiração das vozes senis ajudou na execução dos melismas constantes da música.

AZEVEDO (2003) confirma este pensamento ao relatar que, em pesquisa sobre o processo criativo do Coro Cênico da UFG, "a produção cênica possibilitou a melhora no desempenho vocal, pois a atividade de expressão corporal liberou as inibições corpo/movimento" (p. 91). Em sua conclusão, Azevedo afirma:

No final do experimento detectou-se uma grande melhoria na afinação e na qualidade sonora do grupo, ao se comparar as filmagens das primeiras sessões às últimas. Atribuiu-se ter obtido este resultado qualitativo por meio da inteiração dos benefícios cênicos/corporais (p.93).

Em outras palavras, através de uma proposta de movimentação, trazemos a música para a vivência corporal. A cinestesia ajudará o cantor a compreender e realizar as tarefas musicais, resultando em um grande benefício para o trabalho do grupo.

\section{5 - Ajustes importantes}

É essencial que haja adequação do repertório à proposta de um coro performático. Algumas peças são bastante inspiradoras e propõem um olhar diferenciado. É preciso ter em mente, porém, que a proposta cênica jamais deverá impedir ou atrapalhar a qualidade sonora.

Peças de fácil execução viabilizam a elaboração de movimentação cênica e demais recursos extra-musicais. Já as peças de difícil realização musical demandam muita concentração, limitando assim ousadias cênicas que tirem a atenção dos cantores, dependendo - naturalmente - do perfil e da capacidade do grupo.

Há ainda peças escritas com o propósito de serem realizadas após sugestiva pesquisa sonora, como é o caso 
da composição Mot et em Ré Menor (Beba Coca-Cola) de Gilberto Mendes (OLIVEIRA, 1998). A partir da poesia concreta de Décio Pignatari, o compositor utiliza elementos sonoros inusitados para a época (1966) ou "sonoridades ainda hoje banidas do universo estético-musical da nossa cultura" (VALENTE, 1999, p.194), como sons aspirados, arroto, voz estridente como a do Pato Donald, voz de tenor cacarejada e ruído de ânsia de vômito. Estas indicações conduzem a uma interpretação diferenciada, distante da interpretação de um coro tradicional, onde os resultados de uma investigação cênica só reforçariam a proposta vanguardista do compositor.

Em se tratando de coro juvenil, o cuidado na seleção do repertório precisa ser redobrado, uma vez que outros importantes aspectos podem interferir nesta escolha. A identificação dos cantores, não só com a proposta cênica, mas também com as músicas selecionadas, é o ponto de partida para a realização satisfatória de um projeto com esta exigência. Se os jovens cantores compreendem o que estão cantando, se identificam com o estilo e a estética das músicas e percebem as peças como veículo de sua expressão, poderão tornar a performance bastante intensa, trazendo verdade para sua interpretação.

É importante pensar-se na limitação vocal de um coro juvenil. Algumas peças, por mais interessantes que sejam do ponto de vista expressivo, podem perder sua força cênica se cantadas por vozes que não se adequem à exigência da produção vocal de sua interpretação. A leveza das vozes jovens - ainda que trabalhadas tecnicamente - pode não dar conta do repertório, sobretudo quando as peças se destinam a coro adulto (procedimento bastante comum no canto coral juvenil brasileiro).

Lembremos que adolescentes vivem um período de mudanças vocais intensas, sobretudo as vozes masculinas. Mesmo tendo à frente um grupo de jovens cuja muda vocal já está consolidada, a maturação da voz ainda não ocorreu em sua totalidade. Notas muito graves, por exemplo, não atingem propagação suficiente, uma vez que o próprio indivíduo (seja rapaz ou moça) ainda não consegue tirar total partido de sua ressonância, podendo gerar inclusive um grande desconforto, além de certa frustração. Ou seja, peças com âmbito muito grave para baixos ou contraltos dificilmente terão o peso necessário, podendo comprometer não só a execução musical como também sua força dramática.

0 mesmo desajuste pode ocorrer pelo lado oposto, quando repertório de coro infantil é adaptado ao coro juvenil. Ali, além da inadequação pelo âmbito das vozes em questão, há também uma estética (inerente ao mundo infantil) que pode comprometer a performance. 0 jovem, comumente ávido a se distanciar da infância, pode resistir a abraçar a proposta por conta do constrangimento de se sentir infantilizado pelo conteúdo das músicas escolhidas.
São muitos os cuidados a serem tomados na escolha do repertório e, para que uma derivação maior não prejudique o assunto deste trabalho, fica aqui sugerida a proposta de aprofundamento do tema.

\section{6 - 0 exercício do jogo}

A proposta cênica no coro requer, de saída, uma investigação do corpo e suas potencialidades expressivas. 0 indivíduo é convidado a conhecer melhor suas habilidades físicas, executar movimentos que nem sempre fazem parte de seu cotidiano e explorar sua capacidade expressiva através do gesto. 0 cantor pode trabalhar seu senso de lateralidade e aprimorar sua noção espacial, além de desenvolver o domínio de seu próprio movimento. A compreensão das possibilidades gestuais do indivíduo com seu corpo é fortalecida. No caso de coro juvenil, podemos imaginar o benefício trazido para esta faixa etária, uma vez que a adolescência tem, como tônica, drásticas e rápidas mudanças físicas. 0 autoconhecimento e o conhecimento do corpo do outro são fatores fundamentais para abreviar as angústias da vida do adolescente. RAPPAPORT (1982) afirma:

\footnotetext{
As próprias mudanças corporais que dificultam a sua autopercepção são cuidadosamente observadas nos seus companheiros (notadamente os do mesmo sexo), pois é a partir do conhecimento das mudanças corporais no outro que o adolescente aceitará melhor as suas próprias (além da auto-exploração que se dá pela manipulação do próprio corpo, pela exposição de corpo todo ou de algumas partes diante do espelho, etc.) (p.104).
}

0 processo de investigação cênica leva indiretamente 0 adolescente a um maior contato físico consigo e com 0 outro. Mesmo aqueles mais retraídos são incentivados, através do jogo teatral, a percorrer o caminho da descoberta de suas possibilidades. Embora pareça contraditório, tal prática expositiva poderá auxiliá-lo na riqueza da exploração em si. Outrossim, servir-lhe-á de alívio pela preocupação com a performance, uma vez constatado que a atenção da platéia comumente recai não apenas naqueles que se destacam pela atuação cênica, mas - com importância semelhante - naqueles cuja força dramática destoe do grupo.

Um dos benefícios do exercício cênico em corais é a ênfase na percepção do espaço, do coletivo, do outro. Grupos com preparação adequada adquirem uma postura mais segura no palco e aprendem a se deslocar com mais naturalidade. Costumam poupar o regente da função de organizar o coro à sua frente. Além disso, os cantores aprendem a observar o movimento do todo e de cada um, trabalhando para um bom resultado do coletivo. Há ainda uma facilidade maior na adaptação a diferentes espaços de apresentação.

0 aprimoramento da veia expressiva do grupo dá-se comumente através do exercício da repetição dentro de uma proposta teatral. Não é sugerida aqui uma conotação mecânica e, sim, um recurso de experimentação onde este processo permita a descoberta a partir de sucessivas tentativas. SUZUKI (1983), o renomado autor de método de aprendizado de instrumento, define: 
Devemos esbanjar esforços em nos aperfeiçoar. É um erro acreditar que nascemos com talentos que se desenvolverão sozinhos. Se temos um jeito fácil de realizar algo, isso significa que, por constante repetição, conseguiremos tornar essa habilidade em parte de nós mesmos. "Tornar-se parte de nós" é dizer que o nosso objetivo foi conseguido por trabalho e repetição até o ponto de se ter estabelecido firmemente em nosso consciente. (p.43)

A exploração das possibilidades dos cantores se aprofunda na atividade e novos e mais elaborados caminhos são descobertos. Concomitantemente, este mesmo exercício permite ao coralista estabelecer conexões entre canto e movimento, canto e sentimento, canto e dramaticidade buscando, a cada vez, o aprimoramento da performance. Não obstante, 0 exercício da repetição como instrumento de descoberta cênica permite a execução de um determinado trecho musical diversas vezes, o que poderá também favorecer a realização da parte musical além da parte cênica propriamente dita.

Um dos riscos da exploração cênica reside na cristalização dos recursos. A falta de maior bagagem teatral do coro, a direção despreparada ou mesmo o cantor mal orientado pode fazer o grupo andar em círculos, buscando as mesmas soluções cênicas e abrindo mão do processo criativo e investigativo, tão benéfico para a atividade. Corre-se, inclusive, o risco de imitação de propostas reali zadas por outros corais. A construção criativa demanda tempo e disponibilidade emocional, além de um bom fio condutor.

Uma das experiências interessantes em relação à orientação cênica de corais diz respeito à performance sem líder. Nos casos em que a direção acha conveniente que o trabalho aconteça sem o seu regente, os cantores se vêem na responsabilidade de conhecer profunda e detalhadamente a peça para poder realizá-la, ficando mais concentrados e sintonizados entre si. 0 resultado musical, muitas vezes, acaba sendo melhor justamente pela atenção dispensada à peça já que não há ninguém para reger o coro. 0 senso de autonomia também é estimulado gerando, inclusive, uma maior sensação de compromisso com o grupo.

Note-se que a proposta de coro cênico ou simplesmente a idéia de valorização da expressão cênica de corais exige um empenho diferente dos participantes. Além do trabalho musical - que já não é pouco - o coralista tem que se preocupar com outros aspectos da performance. Esta exigência precisa ser muito bem dosada, pois, dependendo do repertório executado (como já afirmamos anteriormente) e/ou da experiência de palco dos cantores, ao invés de contarmos com um recurso que traga benefícios à produção encontraremos mais um fator de estresse para o grupo, podendo atrapalhar (e muito) o brilhantismo da apresentação. Segundo PUEBLA (2004), corre-se o risco de estragar tanto a parte musical quanto a cênica. ${ }^{5}$

\section{7 - Facilitadores}

Além do trabalho de aprofundamento da expressividade cênica do indivíduo, alguns itens são extremamente estratégicos e facilitadores para o bom proveito da proposta. COSTA (1996) relata sua experiência com o Coral Juvenil do Colégio São Vicente, onde fica claro que certos recursos advindos do teatro foram muito importantes para a solidificação do trabalho coral naquele estabelecimento de ensino. Da mesma forma, AZEVEDO (2003) menciona a importância de recursos cênicos como, por exemplo, a iluminação que não foi possivel de ser utilizada na estréia do grupo, mas que certamente teria se somado ao resultado final do trabalho. Em contrapartida, Azevedo reforça a inclusão das falas antes das músicas, efeito interessante, porém muito difícil de ser executado satisfatoriamente, por depender não apenas da boa projeção vocal, mas, sobretudo de naturalidade cênica para dizer o texto, coisa que nem todo indivíduo consegue alcançar sem um grande treinamento de ator.

Dentre os recursos utilizados em minha experiência e observados nos poucos relatos encontrados, destaco:

7.1 - Tema - o grupo (ou o seu líder) escolhe um determinado tema que norteará toda a montagem. Os cantores, envolvidos na proposta, são convidados a mergulhar num universo específico, estudando muitas vezes a fundo - detalhes interessantes e que Ihes escapariam no dia-a-dia. A escolha pode recair sobre um determinado compositor e sua obra, um estilo musical, uma época marcante ou mesmo algo que inspire compositores, como por exemplo, músicas que falam do mar. Esta estratégia pode ser intensamente explorada nos corais de escola que, com o respaldo de outras disciplinas inclusive, têm aberta a possibilidade de pesquisa de diferentes ângulos do tema proposto, fortalecendo 0 sentido pedagógico dos grupos deste ambiente.

7.2 - Roteiro ${ }^{6}$ - muito embora entendamos que a escolha da ordem das músicas seja fator primordial para uma apresentação, o coral comprometido com direção cênica costuma dedicar maior atenção ao roteiro, sobretudo porque terá percebido a condução de uma peça para outra através de outros canais que não apenas tonalidade, estilo ou grau de dificuldade das músicas. Por conseguinte, a compreensão do roteiro pode trazer maior segurança aos cantores, que perceberão o espetáculo como um todo e o tomarão como seu, ao invés de delegar esta responsabilidade apenas ao regente ou líder.

7.3 - Adereços e figurinos - este recurso costuma ser muito atraente para o jovem cantor, "antenado" com a comunicação visual de si e de seu grupo de afinidade. A criação de uma identidade visual, através da escolha de figurino para o grupo, pode ser uma saudável atividade que instigará os cantores a exercitar a ponderação de 
opiniões e sugestões, além de dar oportunidade de criação, ousadia, ludicidade e questionamento. A própria produção do figurino pode demandar ou desenvolver o senso de organização, determinação, iniciativa, etc.

Já os adereços (esperando-se que sejam de fato pertinentes à montagem) podem ajudar na busca estética do espetáculo, auxiliar no aperfeiçoamento expressivo do indivíduo ou de uma determinada peça ou ainda emprestar um novo apelo visual ao trabalho coral. Deverão ser manipulados previa e incansavelmente para que não se tornem motivo de dispersão do cantor e acabem por atrapalhar a performance.

7.4 - Iluminação - embora nem todo local de apresentação conte com este recurso, é inegável que a iluminação (em sintonia com a música executada) pode trazer magia para o espetáculo, quando em consonância com este; delimita espaços, sublinha passagens, recorta imagens e ajuda a fixar a atenção da platéia, através da atmosfera causada pela escolha de foco e de cores de luz. Não obstante, empresta uma roupagem profissional que em muito estimula os cantores ao capricho de sua participação no trabalho.

7.5 - Texto - utilizado para dar informações extras ao espectador, viabilizar a costura do roteiro ou emprestar poesia à atmosfera da montagem, o texto também é um recurso bastante difundido no meio coral. No entanto, sua utilização esbarra na dificuldade de clareza de intenção teatral. Sendo assim, é mais comum encontrarmos o formato de locução, cujo propósito escapa ao objetivo cênico, mas não diminui sua importância como possibilidade de colorido à performance.

\section{8 - Considerações finais}

Em suma, percebe-se o grande auxilio que a proposta cênica pode dar para a atividade coral. A utilização dos itens facilitadores citados poderá enriquecer a prática coral e envolver os participantes de forma lúdica e prazerosa. Definindo melhor o foco, observa-se que o recurso da expressão cênica pode ajudar na criação e manutenção do trabalho voltado para adolescentes e jovens que, como explicitado através desta pesquisa, constitui imensa lacuna no Brasil, se comparado ao movimento coral entre adultos e crianças.

Surpreendentemente, constata-se que este movimento de parceria expressão cênica/canto coral remonta há mais de três décadas, tendo atestado seus grandes benefícios através dos diferentes grupos advindos desta experiência e que tanta riqueza trouxeram para o panorama do canto coral brasileiro. Ainda assim, pouco material didático é encontrado; tampouco há conhecimento de cursos de formação, aprofundamento e reciclagem desta vertente, a não ser através de escassas iniciativas de poucos profissionais autônomos.

Fica a intenção de que este trabalho sirva de estímulo aos regentes interessados em explorar as diferentes linguagens oriundas do canto coral, que os profissionais das Artes Cênicas se sintam entusiasmados em tomar contato com este universo e que os cantores percebam a grande

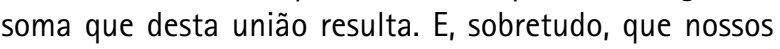
adolescentes e jovens descubram, sem preconceitos, 0 grande prazer proporcionado pelo canto em grupo. 


\section{Referências}

AZEVEDO, Joana Christina Brito de. 2003. Coro cênico: estudo de um processo criador. Dissertação (Mestrado em Música), Escola de Música e Artes Cênicas, UFG, Goiânia.

COSTA, Patricia. Canto coral no $2^{\circ}$ grau: uma alternativa para a continuidade do ensino de música nas escolas. 1996. Monografia (Licenciatura Plena em Educação Artística - Habilitação em Música) - Instituto Villa-Lobos, Centro de Letras e Artes, Universidade do Rio de Janeiro (UNIRIO).

FIGUEIREDO, Carlos Alberto et al. Reflexões sobre aspectos da prática coral. In: LACKSCHEVITZ, Eduardo (Org.). Ensaios: olhares sobre a música coral brasileira. Rio de Janeiro: Centro de Estudos de Música Coral, 2006, p.6-49.

FUKS, Rosa. $O$ discurso do silêncio. RJ: Enelivros, 1991.

KERR, Samuel et al. Carta canto coral. In: LACKSCHEVITZ, Eduardo (Org.). Ensaios: olhares sobre a música coral brasileira. Rio de Janeiro: Centro de Estudos de Música Coral, 2006, p.198-238.

OLIVEIRA, Sergio Alberto de, Coro-cênico: uma nova poética coral no Brasil. In: ENCONTRO ANUAL DA ANPPOM, 12, 1999, Salvador. Anais... Salvador: Fundação Luis Eduardo Magalhães, 1999. p.1-11.

OLIVEIRA, Vilson G., O desenvolvimento vocal do adolescente e suas implicações no coro juvenil "a cappella". 1995. Dissertação (Mestrado em Música) - Instituto de Artes, Universidade Federal do Rio Grande do Sul.

PUEBLA, Reynaldo. 0 canto em cena. In: CONGRESSO INTERNACIONAL SESC/ARCI DE REGÊNCIA CORAL, 2, 2004, São Paulo. Anais... São Paulo: SESC/ARCl, 2004. p.169-170

RAPPAPORT, C., Fiori, W. \&t Davis, C. A idade escolar e a adolescência. Volume 4. São Paulo: EPU, 1982.

SANTOS, Ana Maria Souza dos. Efeito do coro-cênico no desenvolvimento musical: um estudo de caso. In: ENCONTRO ANUAL DA ANPPOM, 12, 1999, Salvador. Anais... Salvador: Fundação Luis Eduardo Magalhães, 1999. p.1-9

SANTOS, Elysianne Araújo dos. A importância dos jogos teatrais e musicais para uma melhor expressividade artística de um coro. 2003. Monografia (Licenciatura Plena em Educação Artística - Habilitação em Música) - Instituto Villa-Lobos, Centro de Letras e Artes, Universidade do Rio de Janeiro (UNIRIO).

SPOLIN, Viola. Improvisação para o teatro. São Paulo: Perspectiva, 1987.

SUZUKI, Shinichi. Educação é amor - um novo método de educação. Santa Maria: Imprensa Universitária - UFSM, 1983.

TUPINAMBÁ, Irene Oliveira Zagari. Dois momentos, dois coros. 1993. Dissertação (Mestrado em Música) - Centro de Pósgraduação, Pesquisa e Extensão - Conservatório Brasileiro de Música, Rio de Janeiro

VALENTE, Heloisa de Araújo Duarte, Os cantos da voz entre o ruído e o silêncio. São Paulo: Annablume, 1999.

Patricia Costa dedica-se ao canto coral desde 1978 como cantora e, desde 1993, como regente, tendo integrado Coro e Orquestra Brasil Barroco, Garganta Profunda e Coro da Southern Illinois University (EUA). Licenciou-se em Música pela UNIRIO em 1996 e trabalha com direção cênica desde 1990. Dirige os corais juvenis do Colégio São Vicente de Paulo e Colégio Cruzeiro (infantil, juvenil e adulto). Ministra palestras na área de coro juvenil e direção cênica para corais. É Professora do Curso de Capacitação e Aperfeiçoamento para Regentes de Corais de Escolas da Secretaria de Estado de Educação do Rio de Janeiro (com o Museu Villa-Lobos) desde 2003. Foi integrante do Coro de Câmera Pro Arte, dirigido por Carlos Alberto Figueiredo, com quem se aprimorou em Regência Coral. Mestranda na UNIRIO sob orientação de José Nunes Fernandes, ministra Coro Infantil/Coro Juvenil na disciplina Processos de Musicalização.

\section{Notas}

1 Para maiores aprofundamentos a respeito da grande mudança estética despertada pelo trabalho destes regentes, procurar em TUPINAMBÁ, Irene Oliveira Zagari. Dois momentos, dois coros. 1993. Dissertação (Mestrado em Música) - Centro de Pós-graduação, Pesquisa e Extensão - Conservatório Brasileiro de Música, Rio de Janeiro; KERR, Samuel et al. Carta canto coral. In: LACKSCHEVITZ, Eduardo (Org.). Ensaios: olhares sobre a música coral brasileira. Rio de Janeiro: Centro de Estudos de Música Coral, 2006, p.198-238. e ALFONZO, Neila Ruiz, Prática coral como plano de composição em Marcos Leite e em dois coros infantis. 2004. Dissertação (Mestrado em Música) - Programa de Pós-Graduação em Música- Universidade Federal do Estado do Rio de Janeiro (UNIRIO).

2 Segundo a Organização Mundial de Saúde, citado por OLIVEIRA (1995)

3 Suray Soren, diretora do Instituto Casa de Cultura (RJ), em palestra/concerto didático durante o I Encontro de Práticas Musicais e Pedagógicas do Instituto Villa-Lobos/UNIRIO, em 18 de junho de 2008.

4 Quando o coro juvenil São Vicente a Cappella (sob direção desta pesquisadora) ensaiava a música Volte Para o Seu Lar (de Arnaldo Antunes, cuja letra teria sido feita especialmente para o ex-presidente Fernando Collor) em 1999, observou-se a falta de intenção de texto dos cantores que, por serem muito jovens, não tinham vivenciado aquele momento político do país. Utilizando situações da atualidade, exercitamos - através de jogos cênicos - sentimentos como revolta, angústia, mágoa, irritação. Trouxemos para o exercício ações que exprimissem os sentimentos encontrados e levamos o resultado para a interpretação da música. Encontrou-se, naquele grupo de adolescentes, uma interpretação tão arrebatadora que, podemos imaginar, seja também fruto desta conexão entre texto e intenção. A força dramática emprestou maior pressão à emissão vocal, fazendo a música crescer qualitativamente, tornando-se durante anos uma das mais bisadas em nossas apresentações.

5 Em depoimento dado à pesquisadora em conversa informal ocorrida em outubro de 2002, no IX Encontro de Corais de Ibiporã, PR, o autor denominou este efeito de sofá-cama: "... não é bom nem como sofá e nem como cama!"

6 Embora este termo - roteiro - seja, principalmente, um aspecto de composição dramatúrgica, será utilizado aqui como roteiro musical, i.e., a organização da disposição das músicas de um espetáculo ou concerto. 